OECDpublishing

\title{
VECTORS \\ OF DIGITAL \\ TRANSFORMATION
}

\section{OECD DIGITAL ECONOMY} PAPERS

January 2019 No. 273 
This paper was approved and declassified by written procedure by the Committee on Digital Economy Policy on 7 November 2018 and was prepared for publication by the OECD Secretariat.

This publication is a contribution to the OECD Going Digital project, which aims to provide policymakers with the tools they need to help their economies and societies prosper in an increasingly digital and data-driven world.

For more information, visit www.oecd.org/going-digital.

\#GoingDigital

Note to Delegations:

This document is also available on O.N.E under the reference code:

DSTI/CDEP/GD(2017)4/FINAL

This document, as well as any data and map included herein, are without prejudice to the status of or sovereignty over any territory, to the delimitation of international frontiers and boundaries and to the name of any territory, city or area.

@ OECD 2019

You can copy, download or print OECD content for your own use, and you can include excerpts from OECD publications, databases and multimedia products in your own documents, presentations, blogs, websites and teaching materials, provided that suitable acknowledgment of OECD as source and copyright owner is given. All requests for commercial use and translation rights should be submitted to rights@oecd.org. 


\section{Foreword}

This report focuses on the many ways digital transformation challenges existing policies. Overwhelmingly, current policies are predicated on tangible products and assets, on fixed geographic boundaries and locations, on transaction costs that limit the scale and scope of interactions and offerings, and on supply and demand conditions that reflect scarcity. The digital transformation is dramatically affecting all of these factors and the efficacy of policies based upon them.

Exposing the underlying nature of the changes induced by digital transformation rather than focusing on the technologies themselves, the report seeks to offer an overarching perspective of the changes at play to understand policy tensions at a more fundamental level. The intent is to outline policy implications across a range of domains to support a holistic and cross-sectoral approach with consistent, mutually supportive policies. The objective is to provide a start towards a checklist against which existing and new policies can be reviewed to see if they are appropriate and fit-for-purpose in the digital era.

The report explores three key areas where digital transformation is affecting the way the economy and society is operating, i.e.: i) scale, scope and speed; ii) ownership, assets and economic value; and iii) relationships, markets and ecosystems. These break down into seven "vectors" of digital transformation that cut through nearly all policy domains. Changes in scale, scope and speed result from the conversion of information into digital bits that can be processed and analysed by computers. The digitisation of information has become exponentially cheaper and faster over the last 50 years and affects the nature of assets that generate value, how ownership is imparted and where value is generated. In turn, these changes affect the structure and operation of markets, supported by digital platforms and thereby create new ecosystems of supply, demand and exchange. These shifts affect how relationships - both economic and social - are developed, maintained and located. For each of the seven vectors the report explores examples of policy implications, and in some cases possible approaches to policy adaptation. While illustrative, the policy examples provide an additional perspective on the vectors.

This report benefits from comments from the OECD Committee on Digital Economy Policy, the Going Digital Steering Group, the Going Digital Expert Advisory Group, a series of Going Digital national roundtables, and responses to a questionnaire gathered from the 14 core OECD Committees participating in the Going Digital project. It also reflects important contributions made by colleagues from across the OECD, as well as outside experts. Key contributors to this report include Angela Attrey, Anne Carblanc, David Gierten, Molly Lesher, Dirk Pilat, Andrew Wyckoff and Brian Kahin, consultant to the OECD. 


\section{Table of contents}

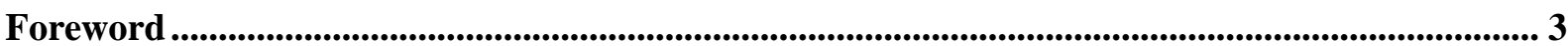

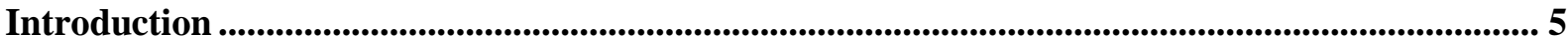

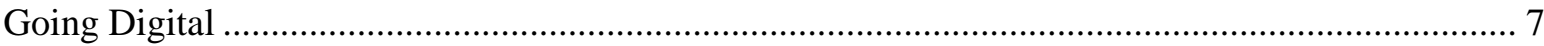

Vectors of Digital transformation ...................................................................................................................... 8

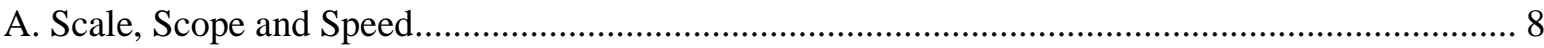

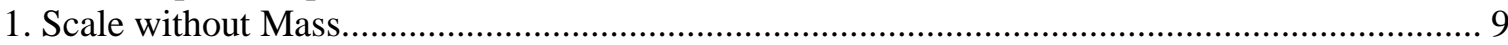

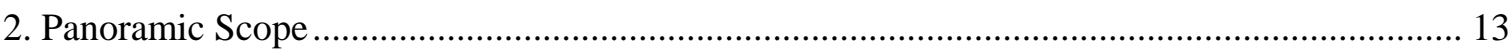

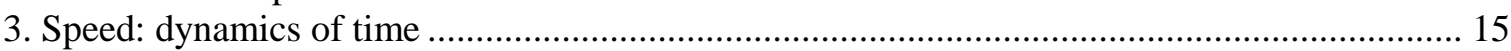

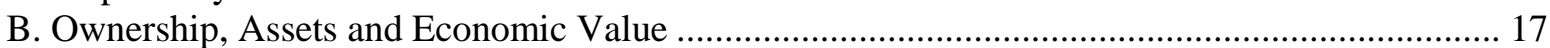

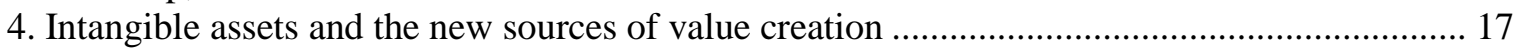

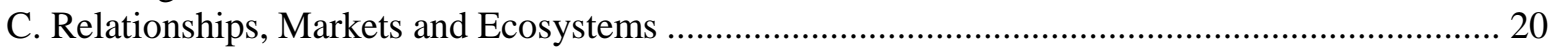

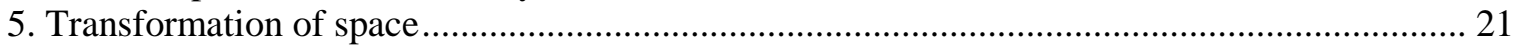

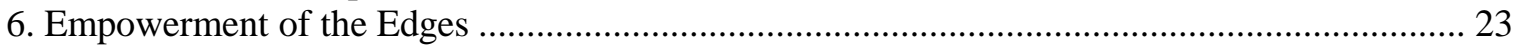

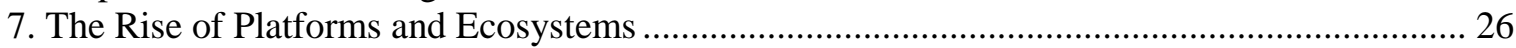

Conclusion ........................................................................................................................................................ 29

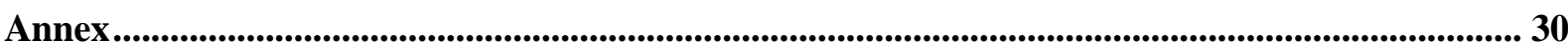

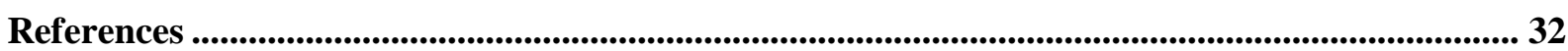

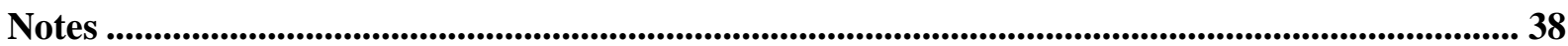

\section{Tables}

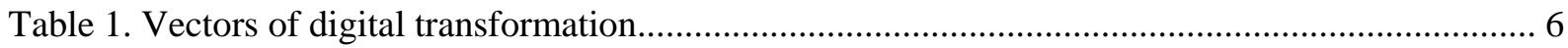

Table 2. Ranking of Internet Firms by Market Valuation, 2018 ........................................................ 12

Table A .1. Checklist for Policy Development in the Digital Era ..................................................... 30

\section{Figures}

Figure 1. The Continuous Advancement of Computational Power: Moore's Law ............................... 8

Figure 2. Business investment in fixed and knowledge-based capital, 2015........................................17

\section{Boxes}

Box 1. Scale without mass - The 'Big 3' in 1990 vs 2016 10 


\section{Introduction}

We are transitioning towards a digital economy and society. Although already underway for nearly half-a-century, the pace of change has quickened with the further deployment of digital infrastructure, the proliferation of smart phones which allows ubiquitous computing, and the generation of huge volumes of data of all kinds. These developments have turned data into an important strategic asset. Many now compare digital transformation with earlier industrial transformations propelled by general purpose technologies like steam or electricity. Whether it is the Second Machine Age (Brynjolfsson et al., 2008 ${ }_{[1]}$ ), the Third Wave (Toffler, 1980[2] ), or Industrie 4.0 (German Federal Ministry for Economic Affairs and Energy, 2018 $\left.{ }_{[3]}\right)$, significant shifts are underway in the economy and in society more generally. With this transformation come rare opportunities to improve welfare and address pressing social issues from health care to education to the environment. Yet such benefits come with new challenges as digital transformation changes the nature and structure of organisations and markets, raises concerns around jobs and skills, privacy, security, social and economic interaction, the formation and composition of communities, and notions of equity and inclusion. Adjustments are inevitable, but there is currently a window of opportunity to shape them with sensitivity and foresight so they can support more inclusive growth and improve well-being.

Reaping the benefits and addressing the challenges of the digital era requires narrowing the gap between technological developments and policy frameworks. Many public policies are the legacy of the pre-digital era. And the difficulty of comprehending the changes underway may delay the review and adaptation of old policies. As in business, digital transformation offers new tools and means of collaboration that may help governments meet policy objectives more effectively. Understanding and acting on the economic and social dimensions of digital transformation is critical as the digital economy becomes the entire economy. OECD's project "Going Digital: Making the Transformation Work for Growth and Well-being" aims to address this challenge by tapping into the expertise of nearly 20 different policy communities and ongoing policy analysis and experimentation across more than 40 countries (OECD, 2017 $\left.7_{[4]}\right)$.

Developing a coherent and whole-of-government approach to digital transformation also requires explaining the changes underway in a non-technical manner that speaks to a wide audience. To do so, this report seeks to concisely present the implications of digital transformation by describing seven key properties - or "vectors" - that affect the design and efficacy of public policies. These vectors are not structurally discrete; they are inherently intertwined and reinforcing. Table 1 provides a stylised summary. In outlining these vectors, this paper offers a tool to better align policies within and across the digital economy and society. The vectors are intended to provide a framework against which existing or new policies can be assessed to ensure that they are well-suited to the digital era. The Annex contains a preliminary check list intended to help in this exercise. 


\section{Table 1. Vectors of digital transformation}

\begin{tabular}{|c|c|c|c|}
\hline & Vector & Description & Examples of policy implications \\
\hline \multicolumn{4}{|c|}{ Scale, scope and speed } \\
\hline 1. & $\begin{array}{l}\text { Scale without } \\
\text { Mass }\end{array}$ & $\begin{array}{l}\text { Core digital products and services, notably software and } \\
\text { data, have marginal costs close to zero. Combined with } \\
\text { the global reach of the Internet, this allows these } \\
\text { products and the firms and platforms that use them to } \\
\text { scale very quickly, often with few employees, tangible } \\
\text { assets and/or no geographic footprint. }\end{array}$ & $\begin{array}{l}\text { The scale effect of being digital may allow the rapid } \\
\text { acquisition of market share - that may also be fleeting } \\
\text { - suggesting that policies ensure that barriers to entry } \\
\text { and innovation are low, and adjust size-based } \\
\text { approaches such as de minimis thresholds and } \\
\text { categorisation based on number of employees. }\end{array}$ \\
\hline 2. & $\begin{array}{l}\text { Panoramic } \\
\text { Scope }\end{array}$ & $\begin{array}{l}\text { Digitisation facilitates the creation of complex products } \\
\text { that combine many functions and features (e.g. the } \\
\text { smartphone) and enable extensive versioning, } \\
\text { recombination and tailoring of services. Interoperability } \\
\text { standards enable the realisation of economies of scope } \\
\text { across products, firms, and industries. }\end{array}$ & $\begin{array}{l}\text { Policies may need to span multiple policy domains, } \\
\text { requiring co-ordination across historically separate } \\
\text { issue areas and a more multidisciplinary perspective. } \\
\text { This may argue for high-level principles as opposed } \\
\text { to narrow rules, a shift from strict harmonisation to } \\
\text { interoperability, and the convergence of policy } \\
\text { oversight authority. }\end{array}$ \\
\hline 3. & $\begin{array}{l}\text { Speed: } \\
\text { dynamics of } \\
\text { time }\end{array}$ & $\begin{array}{l}\text { Digitally accelerated activities may outpace deliberative } \\
\text { institutional processes, set procedures and behaviours, } \\
\text { and limited human attention. Technology also allows the } \\
\text { present to be easily recorded and the past to be probed, } \\
\text { indexed, repurposed, resold and remembered. }\end{array}$ & $\begin{array}{l}\text { Guiding policy principles may be preferred to specific } \\
\text { rules that may be quickly rendered obsolete. New } \\
\text { approaches such as the use of regulatory sandboxes } \\
\text { and the exploitation of data flows and big data } \\
\text { analytics may both accelerate and enable more } \\
\text { iterative and agile policy making. }\end{array}$ \\
\hline \multicolumn{4}{|c|}{ Ownership, assets and economic value } \\
\hline 4. & $\begin{array}{l}\text { Intangible } \\
\text { Capital and the } \\
\text { New Sources of } \\
\text { Value Creation }\end{array}$ & $\begin{array}{l}\text { Intangible forms of capital like software and data are } \\
\text { receiving greater investment. Sensors that generate } \\
\text { data allow machinery and equipment (e.g. jet engines, } \\
\text { tractors) to be incorporated into new services. Platforms } \\
\text { enable firms and individuals to monetise or share their } \\
\text { physical capital easily, changing the nature of ownership } \\
\text { (e.g. from a good to a service). }\end{array}$ & $\begin{array}{l}\text { Policymakers may want incentives to investment } \\
\text { more aligned with the economics of digital innovation } \\
\text { and production (e.g. R\&D, data, IP). The ability to } \\
\text { efficiently market services derived from capital } \\
\text { equipment (as opposed to direct investments) may } \\
\text { have implications for incentives to invest as well as } \\
\text { measures of investment and productivity. }\end{array}$ \\
\hline \multicolumn{4}{|c|}{ Relationships, markets and ecosystems } \\
\hline 5. & $\begin{array}{l}\text { Transformation } \\
\text { of space }\end{array}$ & $\begin{array}{l}\text { Thanks to their intangible, machine-encoded nature, } \\
\text { software, data, and computing resources can be stored } \\
\text { or exploited anywhere, decoupling value from borders, } \\
\text { and challenging traditional principles of territoriality, } \\
\text { geographically-based communities and sovereignty. } \\
\text { This separation creates opportunities for jurisdictional } \\
\text { arbitrage. }\end{array}$ & $\begin{array}{l}\text { Policies relying on geographical specifications like } \\
\text { nexus, rules of origin or defined markets may need to } \\
\text { be revised, to consider other points along the process } \\
\text { of value creation and distribution (e.g. location of value } \\
\text { creations vs. value delivery). This separation of value } \\
\text { creation from use increases the need for policy } \\
\text { interoperability between countries and regions. }\end{array}$ \\
\hline 6. & $\begin{array}{l}\text { Empowerment } \\
\text { of the Edges }\end{array}$ & $\begin{array}{l}\text { The "end-to-end" principle of the Internet has moved the } \\
\text { intelligence of the network from the centre to the } \\
\text { periphery. Armed with computers and smartphones, } \\
\text { users can innovate, design and construct their own } \\
\text { networks and communities through mailing lists, } \\
\text { hyperlinks and social networks. }\end{array}$ & $\begin{array}{l}\text { Public policies will need to consider reorientation } \\
\text { away from centre (large institutions) and toward more } \\
\text { granular units like individuals. This includes policies } \\
\text { ranging from digital security and data stewardship to } \\
\text { labour and social policies. }\end{array}$ \\
\hline 7. & $\begin{array}{l}\text { Platforms and } \\
\text { Ecosystems }\end{array}$ & $\begin{array}{l}\text { Lower transaction costs of digital interactions reflect the } \\
\text { development not only of direct relationships but also } \\
\text { digitally empowered multi-sided platforms, which in turn } \\
\text { contribute to further reducing transaction costs in many } \\
\text { markets. Several of the largest platforms essentially } \\
\text { serve as proprietary ecosystems with varying degrees of } \\
\text { integration, interoperability, data-sharing, and openness. }\end{array}$ & $\begin{array}{l}\text { Public policies need to reflect on the shift of markets } \\
\text { toward platforms which may increase efficiencies } \\
\text { while re-intermediating and re-concentrating activity } \\
\text { that may have implications for maintaining sufficient } \\
\text { competition. Governments may need to rethink the } \\
\text { provision of public services to take advantage of } \\
\text { platforms. }\end{array}$ \\
\hline
\end{tabular}




\section{Going Digital}

Digitisation is the conversion of analogue data and processes into a machine readable format - i.e., $1 \mathrm{~s}$ and $0 \mathrm{~s}$ that can be read and manipulated by computers. It is commonly associated with the conversion of analogue content into binary code, as happened in the consumer market for entertainment with the introduction of CDs and DVDs, but it can be used in multiple ways that makes data vastly more productive than its analogue equivalent. This is thanks to digital code (i.e. algorithms that can interpret, manipulate, process, and transform any form of digital data) activated by software into executable instructions. Digitalisation is the use of data and digital technologies as well as interconnection that results in new, or changes to existing, activities, while digital transformation refers to the economic and societal effects of digitisation and digitalisation.

Data is at the heart of the digital transformation. It is not new, but gathering, storing and managing data was cumbersome and labour-intensive before it became digital. Standards for categorising, structuring, linking and moving digital data have made it amenable to algorithmic management, which has made it more meaningful and usable, and therefore more valuable. Today, the capacity for acquiring and managing data is expanding rapidly through the proliferation of devices, services, and sensors throughout economy and society. This phenomenon has been described by terms like "big data" and "Internet of Everything". In this highly connected environment, algorithms not only create value from data, but the data in turn improves algorithms, leading to "machine learning" and the development of artificial intelligence.

Increasingly linked to physical resources and conditions, this growing interaction between data, algorithms, things and people translates into a "data-driven" economy and society. This transformation makes data a resource and an asset to be traded that underpins the trade of other goods and services (OECD, 2015 $[5])$. But data, and the emergence of a data-driven economy and society, create their own challenges: how to fully exploit the potential of data to stimulate innovation and productivity while adhering to policy objectives such as protecting privacy and intellectual property rights, and ensuring security. Striking this balance will be difficult, but recognising the relative costs and benefits of enhanced sharing and re-use of data is essential to making digital transformation work for growth and wellbeing. 


\section{Vectors of Digital transformation}

The shift to digital products, digitally-enabled markets, and their interaction has distinct basic properties that differ from analogue or physical equivalents and antecedents. These properties, often disruptive, can affect policy making in various ways. In order for policies to be effective in the digital economy and society, it is necessary that they account for these properties which are interdependent and overlapping but fall into three broad categories: a) Scale, Scope and Speed; b) Ownership, Assets and Economic Value; and c) Relationships, Markets and Ecosystems.

\section{A. Scale, Scope and Speed}

Digital technology has been a driving force along three interrelated dimensions: scale, scope and speed. Rapid progress along and across each of these dimensions has in turn propelled digital innovation. A fundamental driver is the exponential, as opposed to linear, increase in processing power for nearly 50 years, with the number of transistors per square inch in an integrated circuit doubling every 18-24 months, an evolution postulated by Moore's "law" (Figure 1). This development has been highly transformative as it has allowed a drastic miniaturisation of computers and a sharp reduction in the cost of computing. In terms of processing power, we now carry 1990-era super computers in our pockets (Experts Exchange, 2018 ${ }_{[6]}$ ), which can execute complex computations and enable a vast number of functionalities (i.e. phone, camera, voice recognition, location, cloud services) (Varian, 2017 $[7]$ ) in one device. At the same time, the intangible nature of digital information and the global reach of the Internet permit rapid scaling of purely digital products and many Internet-based services.

Figure 1. The Continuous Advancement of Computational Power: Moore's Law

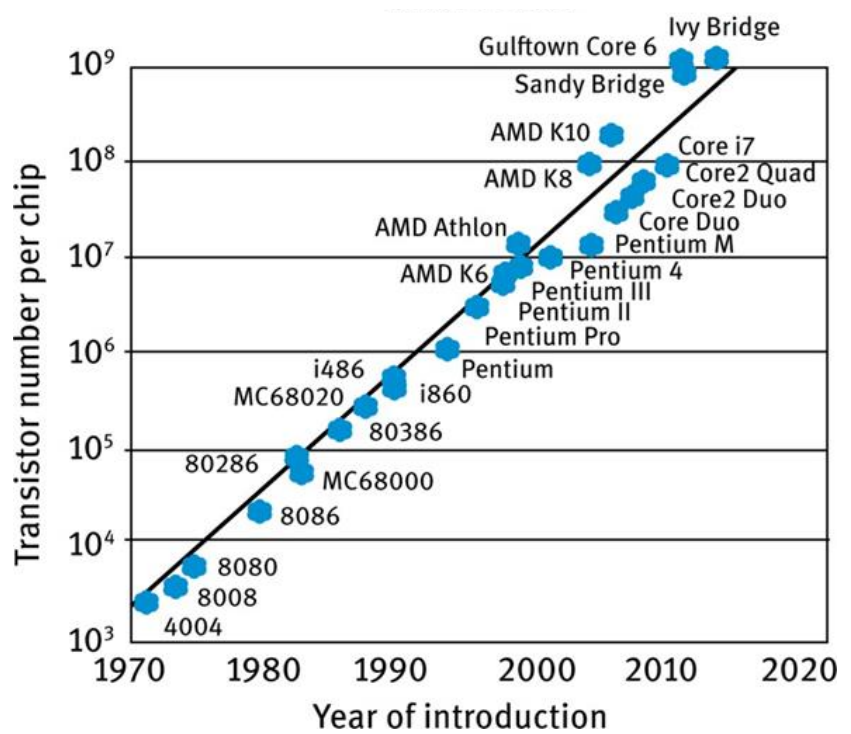

Note: "Moores' Law" was predicted by the co-founder of Intel®, Gordon Moore, in 1965 and slightly corrected in 1975.

Source: (Ostendorf and König, 2015[8]) 
These factors work together to create complex economic and social effects that reflect a fundamental change in the nature of production (Box 1). This includes the growing role of scale in operations and demand-side economies (i.e. network effects that increase value as more users enhance the utility of the product), as well as of scope (especially in the richness or completeness of product offerings). In addition, high speed to market combined with economies of scale and scope can contribute to "winner take most" outcomes.1 Along with progress in algorithms, these factors combine to produce change at a staggering pace that may exceed the ability of some policies and institutions to respond and adapt. This pace is exhilarating to many who exploit the new-found convenience and "permission-less innovation" that it enables; for others, it fuels apprehension about the future, a sense of a loss of control, and an erosion in the confidence in the ability of governments to cope with this change and to look out for their welfare (Anderson and Rainie, 2018 $8_{[9]}$ ).

\section{Scale without Mass}

Unlike physical products, which tend to have high fixed costs and substantial marginal costs that decline with scale, digital products tend to have mainly fixed costs and low, close to zero, marginal costs. This characteristic combined with the global distribution enabled by the Internet allows successful firms and platforms to scale quickly, internationally, sometimes with very few employees or tangible assets (Brynjolfsson et al., 2008 ${ }_{[1]}$ ).

A good example of this phenomenon is WhatsApp, a mobile messaging company. When it was bought by Facebook in 2014 for USD 19 billion, it had 300 million active users and processed 50 billion messages per day but only employed 55 people (Burnham, 2014 [24]). While possibly an extreme case, similar fast growth has been seen by Spotify as it grew from basically zero paid subscribers to 50 million by 2016 and Netflix who had fewer than 10 million paid subscriptions in 2007 and now only a decade later is approaching 100 million (Meeker, 2017 $[25]$ ). In both the cases of Spotify and Netflix the availability of cloud computing facilitated this fast growth and meant that the "mass" of ICT equipment was borne by another firm (Amazon, 2014 ${ }_{[26]}$ ).

In contrast to WhatsApp, the dominant messaging service of 1970 was AT\&T who enjoyed a near monopoly position in the US telephone market as it connected 55 million households, transmitted about 500 million calls a day, and employed nearly a million people (Toffler, $1980_{[2]}$ ). This growing role of scale without mass may be among the factors contributing to the divergence in productivity between global leaders and lagging firms that emerges from recent OECD work (OECD, 2015 $5_{[5]}$ ) (Andrews, Criscuolo and Gal, 2016 ${ }_{[27]}$ ), which is particularly strong in the Information Communication Technology (ICT) services industry.

The capacity to scale without mass may also affect competition in some markets. Firms that sell software or digitally-delivered services can possibly scale up faster and more easily than other firms, thanks to lower costs of production, easier penetration of multiple markets and a higher intensity of knowledge assets, which can be re-used at close to zero marginal cost. Such digitally enabled industries are typically characterised by: (i) direct network effects whereby the value of the service provided by a product increases with the number of users, and/or indirect network effects, whereby the number of users of one service increases the value of complementary services (Experts Exchange, 2018 [6] $_{\text {) }}$ (ii) economies of scope in data collection and analysis, and, as a result, (iii) high and increasing levels of price and product differentiation. Over time, these characteristics may help industry leaders to pull ahead, as these factors may represent an additional obstacle to the entry of new players and hinder the growth of competitors. If only a few firms have access to such 
technologies and the rate of adoption is slow due to the need for complementary investments (e.g. skilled staff, organisational structure), market power may increase for a few pioneers and stall or even decrease for others, thus generating potential winner-takesmost dynamics (Varian, 2017 $[7]$ ).

\section{Box 1. Scale without mass - The 'Big 3' in 1990 vs 2016}

Many policies are predicated on a twentieth century model of economic production and distribution, perhaps best symbolised by the dominant industry of the day: automobiles. In 1890, there were over 1800 automobile manufacturers in the United States (Kimes and Clark Jr., $1996_{[10]}$ ), but within 70 years the automotive industry had been condensed to the 'Big 3' - Ford, General Motors and Chrysler. A similar pattern emerged in both Germany (Volkswagen, Mercedes-Benz and BMW) and Japan (Toyota, Nissan and Honda).

The concentration of the automotive industry reflected the use of interchangeable parts, streamlined assembly and the benefits of economies of scale at every stage of the production process to facilitate mass production. The dominance of the Big 3 firms prompted changes across policy domains, from labour laws to health care to pensions to environmental rules to trade policy, in the United States, Germany and Japan. For example, Ford Motor Company famously increased the wage of its assembly line workers in 1914 to USD 5 per day, doubling the average wage for unskilled workers at the time and spurring policy discussion about the role of minimum wages (The Learning Network, 2012 $[11]$ ).

The growth of the automotive industry also relied on the use of more physical resources, namely more materials, labour and capital. Consequently, expansion in both domestic and overseas markets involved a physical presence, which required an adherence to local rules and regulations. By 1990, the American Big 3 produced almost 10 million vehicles and had 1.2 million employees, revenues of USD 250 billion and a market capitalisation of USD 36 billion between them (Chui and Manyika, $\left.2015_{[12]}\right)$. The Big 3 currently operate more than 200 assembly plants and other facilities in the USA (American Auto Council, 2016 $6_{[13]}$ ), while the American automotive industry produced over 12 million motor vehicles in 2016 (OICA, 2017 $[14]$ ). As of 2017, of the world's top-10 MNEs ranked by assets (excluding businesses in finance or oil), motor vehicle firms occupied four spots while Apple was the only large tech firm. ${ }^{2}$

An analogue to the power of the Big 3 during the 20th century is the market dominance enjoyed by Alphabet, Facebook, Amazon and Apple, whose combined services underlie an increasing share of activity online. Alphabet's biggest subsidiary, Google, holds over $80 \%$ of the market share in digital search engine services (Statcounter, 2017 $[15]$ ), while social media site Facebook boasts over 2 billion monthly active users (Facebook, 2016 $\left.{ }_{[16]}\right)$. Similarly, e-commerce platform Amazon accounts for almost one third of online transactions (Wahba, 2017 $7_{[17]}$ ). In 2016, Apple Inc., a manufacturer of high-value consumer electronics and an online services company, earned the ninth highest revenues of any company in the world (Fortune, $2017_{[18]}$ ), and was estimated to make more than $80 \%$ of the profit in the global smartphone market (Van Alstyne, Parker and Choudary, 2016 ${ }_{[19]}$ ). In 2016, Alphabet, Facebook, Amazon and Apple had combined revenues of USD 469 billion (1.9 times the Big 3), but had a market capitalisation of over USD 2 trillion (Financial Times, 2017 [20] $_{\text {) }}(8$ times the Big 3) with just 539000 employees (less than half the Big 3) (Alphabet, 2016[21]) (Amazon, 2016[22] $)$ (Apple, 2016 $6_{[23]}$ ) (Facebook, 2016 $[16]$ ).

Sources: (Kimes and Clark Jr., 1996[10]); (The Learning Network, 2012[11]); (Chui and Manyika, 2015[12]); (American Auto Council, 2016[13]); (OICA, 2017 $[14])$; (Statcounter, 2017 $[15])$; (Facebook, 2016[16]); (Wahba, 2017 $[17])$ ); (Fortune, 2017 $[18]$ ); (Van Alstyne, Parker and Choudary, 2016 ${ }_{[19]}$ ); (Financial Times, 2017[20]); (Alphabet, 2016[21]) (Amazon, 2016[22]) (Apple, 2016[23]).

At the same time, some degree of market power might be both inevitable and sometimes even necessary. Markets rarely correspond to the theoretical textbook case of perfect competition where prices equalise to firms' marginal costs and no market power exists. 
Moreover, some degree of limited protection from competition, e.g. of the nature of the 20 -year patent term granted to inventors, might be needed ex ante to strengthen innovators' incentives to invest. However, if companies acquire ever-larger market shares, including through buying up start-ups and SMEs, and market concentration increases, firms may be able to further insulate themselves from competition. This, in turn, may reduce aggregate productivity growth through lower technical efficiency and worsen the allocation of inputs across firms and industries. Market power might also decrease the leading firm's incentives to innovate and slow down the diffusion of technologies between firms at the frontier of technology and other firms, thus contributing to growing divergence among firms (Andrews, Criscuolo and Gal, 2016 $[27]$ ).

Because they leverage human capital, economies of scale can raise fundamental concerns about productivity, employment and growth. The advantages of scale may encourage and justify the "Internet model" of bearing short-term losses to achieve scale rapidly in return for market share and the prospect of future profitability (Bezos, 1997 ${ }_{[28]}$ ). In the short term, superabundance clearly benefits consumers as choice expands and prices are low, but it may, at a later stage, lead to consolidation and limited choice.

\section{Examples of policy implications}

The most apparent policy implication associated with the "scale without mass" of some digitally empowered businesses, especially when they benefit from network effects, is the potential for increasingly concentrated markets. In principle, this raises no competition problems if any resulting market power is temporary and the resulting rents are eroded by competition from other firms and new business models. In fact, the history of the digital economy is punctuated by once dominant firms that have not been able to maintain their position - few now remember AOL, AltaVista or MySpace - partly because it is often easy to replicate an idea and initial barriers to entry are low. As is the general practice, policy makers should therefore be attentive that an environment prevails that is not thwarted by anti-competitive behaviour, the erection of barriers to entry or the misuse of a dominant gateway position (Anderson and Rainie, 2018 ${ }_{[9]}$ ). Non-price competition (e.g. barter for data, reputation, seamless interface between products), related to quality and first-mover effects, may warrant consideration where the digital business does not explicitly charge users for the provision of services.

In the digital environment, policy makers may also need to get used to the fall of seemingly dominant, leading firms that have difficulty navigating the transition from an analogue to a digital business model. Kodak is a case in point. At its peak Kodak was a worldrecognised brand and produced $90 \%$ of the film used in the United States. Even though it held an early patent on digital photography (Estrin, 2015 $5_{[29]}$ ) and launched one of the first photo sharing web sites (Anthony, 2016 $6_{[30]}$ ), it struggled and eventually failed to convert its business model. As the digital transformation cuts through all sectors of the economy, policy makers need to prepare for a period of sustained "creative destruction" that will affect not only traditional firms but even digitally adept firms like Nokia or Blackberry (RIM) whose main business gets hit by new technologies and innovative business models. As seen in Finland and Canada this churn can sometimes take on macro implications.

The importance of "scale" in the digital economy also raises issues for policy makers as regards the size of domestic markets. While digital start-ups may need little "mass" to launch and grow, they do require a user community that is large enough to generate network effects and attract sufficient attention in an increasingly crowded environment. Larger markets offer participants low marginal costs, the ability to optimise on the basis of one set 
of policies and reduced transaction costs, and domestic firms may often be among the first to benefit. Large markets also benefit from a greater diversity of participants, along with a higher level of resilience that goes with size and heterogeneity. Being small and open globally may not be a sufficient base for spawning global digital firms which currently are mainly US- or, Chinese-based (Table 2). Gaining scale may require regulatory harmonisation as the European Union is currently seeking to do through the digital single market initiative or regulatory interoperability as is the objective of the privacy shield framework (U.S. Department of Commerce, 2017 $[31]$ ) as well as the APEC Privacy Framework (APEC, 2015 [32]).

Table 1. Ranking of Internet Firms by Market Valuation, 2018

Public / private firms ranked by market value in billion USD

\begin{tabular}{clccc}
\hline RANK & Company & Region & $29 / 05 / 2013$ & $29 / 05 / 2018$ \\
\cline { 2 - 5 } 1 & Apple & USA & 418 & 924 \\
2 & Amazon & USA & 121 & 783 \\
3 & Microsoft & USA & 291 & 753 \\
4 & Google / Alphabet & USA & 288 & 739 \\
5 & Facebook & USA & 56 & 538 \\
6 & Alibaba & China (People's & - & 509 \\
& & Republic of) & & 483 \\
7 & Tencent & China (People's & 71 & 152 \\
& & Republic of) & & 150 \\
8 & Netflix & USA & 13 & 133 \\
9 & Ant Financial & China (People's & - & 100 \\
& & Republic of) & & 94 \\
10 & eBay + PayPal & USA & 71 & 84 \\
11 & Booking Holdings & USA & 41 & 75 \\
12 & Salesforce.com & USA & 25 & 72 \\
13 & Baidu & China & 34 & 56 \\
14 & Xiaomi & China & - & 52 \\
15 & Uber & USA & - & 31 \\
16 & Didi Chuxing & China & - & 30 \\
17 & JD.com & China & - & 30 \\
18 & Airbnb & USA & - & - \\
19 & Meituan-Dianpin & China & - & \\
20 & Toutia & China & & \\
\hline
\end{tabular}

Source: (Meeker, 2018[33])

Note: *eBay + Paypal combined for comparison purposes though PayPal spun-off of eBay of 7/20/2015. Market value data as of 5/29/2018.

Beyond issues of competition and competitiveness, "scale without mass" may challenge policies that are currently oriented towards "big" or "small" businesses. New digital businesses may be big in terms of revenue, market share and influence but not by traditional measures of mass (employees, capital equipment or buildings) many of which are a basis for policy (preferential treatment based on size, incentives to invest, and incentives to locate). The scale effects of being digital may provoke a debate about what qualifies as being de minimis and so eligible for exemptions from certain policies (e.g. duties, taxes, social costs) or what qualifies as "small" and thereby benefits from certain rules or subsidies. This challenge may be further aggravated by the Internet that enables "micromultinationals" (eBay, 2014 $[34]$ - small businesses that sell globally with relatively little effort and take influential or leading positions in global value chains. These micro- 
multinationals may also be able to benefit from differences in national policy environments for strategic or financial advantage ("jurisdictional arbitrage") such as differences in tax regimes or rules governing data that have thus far only been available for large MNEs.

This "born global" feature enabled by digitalisation naturally focuses attention on extraterritorial effects and contrasts with governments that are configured to treat domestic and foreign policy separately, often under different rules. The ability of many digitally empowered business models to have a significant presence in a market jurisdiction without mass or "physical presence" (e.g., employees, office space) constrains the ability of governments to impose direct and indirect tax liabilities in respect of activities that may be connected to the jurisdiction through the presence of their customers. In the indirect tax area, for example, the International VAT/GST Guidelines have been developed to help enshrine the "destination principle" at the heart of consumption taxes and new tools and mechanisms have been developed to allow governments to effectively collect consumption taxes associated with digital sales in the cross border context. In the area of direct taxes, such as corporate income tax, these challenges have given rise to instances of base erosion and profit shifting (BEPS) as the rise of "scale without mass" raises challenging questions around the drivers and location of value creation.

While no firm can scale entirely without mass, the strong role of scale in the digital economy also implies that a firm can go global without establishing many (if any) plants, hiring many employees or developing governance mechanisms to meet a variety of international regulatory obligations. This is in stark contrast to brick-and-mortar industries (Box 2), where global expansion requires some physical presence and adherence to local policies concerning labour, the environment and taxes. Digital production may limit the ability of (but may in some cases negate the need for) governments to impose their policies (e.g. tax, labour, environment) since production may not occur within their borders. This in turn poses challenges for the measurement and interpretation of economic phenomena, including the appropriate identification of outputs and inputs, which is necessary to assess productivity.

\section{Panoramic Scope}

"Economies of scope" were once viewed as a benefit realised by conglomerates that could support many product lines by sharing common costs such as legal, finance, accounting, and marketing, or through vertical integration, which obviated the need and costs of complex contracting between firms. The ability to categorise, code and store digital information in standardised form reduces a broad range of transaction costs (Goldfarb and Tucker, $2017_{[35]}$ ), providing the basis for more efficient interaction. In turn, this provides firms with the ability to tailor products to individuals in near real-time, greatly increasing economies of scope, leading to new business models (e.g. the "long tail"), blurring sectoral boundaries (e.g. one firm being in retail, ICT services and fulfilment/logistics), and changing the landscape for market competition.

In the complexity of the digital environment, demand-side economies of scope are generated by the capacity to manage applications in a way that reduces learning costs and attracts, engages, and maintains customer relations over time. Customers may invest in learning how to interact with applications - an intangible sunk cost that may make them reluctant to switch to a competitor, especially if they cannot easily retrieve their data in readily reusable form.

Economies of scope are also reflected in the capacity of digital technology to amass vast functionality in small useful packages through efficient combination, integration, 
miniaturisation, and virtualisation. This is achieved through modularity, an essential architecture that allows functions to interconnect through well-defined interfaces made possible by digitisation. By modularising functionality, it becomes possible to redesign specific components separately without jeopardising the operation of the whole product. Scope is also manifested in combinatorial innovation and engineering which allows functional expansion. This is best seen in the smartphone that typically combines telephony, navigation, photography, music, and enables customers to add a host of other applications in one device (Varian, 2017 $[7]$ ).

As data-driven business models proliferate across sectors from agriculture to finance to transportation to retail, data savvy firms may have a comparative advantage enabling and inducing them to broaden their scope and expand to additional sectors either as new entrants or through acquisitions of existing firms. In doing so, they may introduce dramatically new products and approaches based on big data analytics which may disrupt incumbent firms operating in only a sectoral (vertical) level. One example for such types of businesses are online platforms that operate in multiple markets.

\section{Examples of policy implications}

Like economies of scale, economies of scope tend to favour large firms with the resources to combine functions, and may put small firms at a disadvantage. However, the effects of economies of scope are less straightforward than those of economies of scale. While the digitalisation of commerce reduces routine transaction costs, which benefits small firms as well as large, it has little effect on the burden of regulatory compliance. Small firms may find it harder to absorb the costs associated with multiple regulatory requirements engendered by an expanded scope of offerings. Policymakers may therefore wish to consider whether they can excuse aspects of compliance for small firms -- the de minimis issue raised above.

More generally, scope challenges regulators and policy makers as policy implications may extend across what are in many cases separate policy domains delineated by ministries, departments or agencies. This may require coordination, harmonisation, or integration, often demanding a multidisciplinary perspective. This has been the case in communications regulation, which typically now covers data, voice and video leading to a reorganisation in many countries. This phenomenon may become common. For example, the introduction of automated vehicles will have an impact on tax, environmental, and labour policies, as well as transportation and urban planning. High-level principles that provide a common policy framework can help align different parts of government. Likewise, national strategies and high-level co-ordination councils may help, although such initiatives are frequently limited by implementation through agencies or ministries which are often segmented by silos of knowledge and information, stove-piped functions and budgetary authority, and legacy administrative structures.

As many economic sectors become data-driven, governments will need to develop expertise with data stewardship including privacy and security in all policy domains. This will confront demands for hierarchical accountability and efficiency that discourage overlap or redundant activities, and may lead to arguments for concentrating digital policy expertise in a single group instead of spreading the competency. No one right formulation is apparent, but it is clear that digital expertise will become a basic skill set needed by all parts of government.

An important policy implication for the vector of "panoramic scope" is the central and strategic role of standards development. Like traditional standards typically based on 
identity or similarity (e.g. tensile strength of different types of steel), digital standards contribute to economies of scale and competition among a variety of producers. However, in the digital sphere, standards also are a means of achieving scope through interoperability and extensibility, thereby enabling more combinatorial innovation. Digital standards are often anticipatory (allowing new products to develop with a technical specification in mind) and flexible (responding to changes in technology and business conditions, including the need to interoperate with other evolving standards), while traditional standards are designed to be static and stable. It is estimated that some $85 \%$ of new standards are for digital technology (Blind and Kahin, 2017[36]). Consequently, standards development become a critical element of the digital policy mix and warrant attention beyond narrow technical groups.

Lastly, as data analytics becomes fundamental to many sectors, and data savvy firms enter traditional sectors and promote data-driven business models, they may introduce unorthodox and disruptive approaches that challenge incumbents with established business models. Policy makers should be open to these new entrants and the benefits that they may bring and assess calls from incumbents for "a level playing field" to ensure that they ensure robust competition rather than protecting firms from the need to adapt.

\section{Speed: dynamics of time}

Digitalisation accelerates economic and social activity: markets clear faster, ideas spread more quickly, the time buffer associated with distance shrinks, as does the time it takes to identify, engage and develop a community. Advantage increasingly goes to first movers and fast followers, and to agility supported by rapid, iterative learning. This property underpins three practices that have been associated with the digital era: 1) businesses models that promise to "move fast and break things" (Taplin, 2016 $\left.6_{[37]}\right) ; 2$ ) achieving scale before profits ${ }^{3}$, which is facilitated by the near zero marginal cost of communicating and sharing information over space that can in turn lead to superstar effects or winner-takemost outcomes; and 3) launching an idea before it is perfected with the assumption that iterative learning will come from its use in the market. These characteristics motivate firms to learn quickly - including how best to exploit a slow-moving policy environment. Moreover, by their ability to quickly scale and learn, firms can attract a customer base, which can also help them create a supportive constituency for any possible policy debate.

Time is commonly perceived as unidirectional and monotonic, but both characteristics can be affected by digital transformation. Digitisation enhances the use and value of past information by making it more accessible, useful, and reusable. Digitisation has made text searchable, compressible, easily manipulated, and linkable, and it enables the products of the past to be preserved, probed, indexed, repurposed, reinterpreted, and resold. This ability to easily reference and recycle past information is one of the factors driving expansion of scope, discussed above. At another level, digital transformation also enables time to be managed by various gatekeepers, for example as network operators opt to provide priority to some services. Another aspect of how policies are adapting to the new dynamics of time is the emergence of rules that seek to limit the access to information that has been deemed to be false, inaccurate or has lost its relevance over time and has earned the "right to be forgotten".

The technological capacity to preserve and use past information, and to combine it with new information continues to support a rapid expansion of the digital economy. As a result, a limited supply of human attention faces demand from a growing abundance of content, multiple devices, and expanding electronic communication - much of this driven by 
advertising. Digital technology allows individuals and enterprises to prioritise and manage this overload through sophisticated software and through asynchronous communications and time shifting. E-mail need not be answered in real time, yet other digital services are optimised for real-time communication. Teamwork and collaboration no longer require physical collocation, but can build on expertise from remote time zones as needed. Content can be stored, or it can be streamed on demand. The ability to manipulate time blurs what used to be clean divisions between working hours and leisure time.

Digital time may be accelerated but this tends to occur unevenly across different parts of the digital ecosystem. Operating systems, standards, and Internet protocols change slowly, as they are hostage to backward compatibility and a vast embedded system. Data, however, is the transformative element, because it can be recast, translated, and reused algorithmically. Moore's Law was broadly predictable for many years, but there are many steps between the brute capabilities of data processing and practical applications in the economy and society, partly due to the slow, iterative process of organisational change, process innovation and the development and introduction of new skills.

\section{Examples of policy implications}

Digitally empowered firms can respond to opportunity, test various responses and execute quickly - and increasingly must do so in the face of global competition, amplified by digital transformation. Within the firm, planning is private, and decisions may be accelerated by executive fiat. Tactically, it may make sense to act fast, and, if necessary, ask forgiveness later (CHIPS Magazine, $2017_{[38]}$ ). Although this should compel new configurations of policy, shifts are typically slow in coming, cautious, and legally, politically, and bureaucratically constrained. Policy development and implementation processes are purposefully deliberative and thereby inherently slow (except in crises). Governments must follow prescribed procedures in dealing with a full spectrum of stakeholders from individual citizens to competing commercial interests. In a regulatory environment, the gap can grow because of bias towards inertia and the influence that incumbent interests may exert through accumulated resources and experience with regulatory and political processes. In this context, the distance between public governance and private enterprise grows, especially for start-ups operating in an accelerated, high risk, competitive environment that typically do not have the resources to participate effectively in policy processes (Kahin, 2016 $6_{[39]}$ ).

Accelerating policy making to Internet speed is neither possible nor desirable, but without adequate action, opportunities may be lost and path dependence may set in. Ex ante regulation can be problematic if not fully grounded in experience and insight which is difficult to obtain in periods of rapid transformation that generate a stream of new technologies. Ex post regulation may face resistance from embedded interests. At the same time, too frequent (or in some cases the absence of) policy intervention may create uncertainty that limits investments and innovation. Countries with a well-established and elaborated policy framework and constituencies built up over hundreds of years may be at a disadvantage to emerging economies or countries that have recently switched from one system (e.g. communism) to another, providing them with "leap frog" opportunities.

Cognisant of the slow pace of policy making, policy makers are increasingly allowing experimentation on a limited, controlled basis via what is being called policy "sandboxes" or policy labs (Financial Conduct Authority, 2015 ${ }_{[40]}$ ). In addition, lessons can often be learned from other jurisdictions, including developing countries that may benefit from relatively few legacy policies, or from small countries that may experience a 
disproportionate impact of the digital transformation, forcing a change and so serve as "canaries in the coal mine". Both cases underscore the need for multilateral venues that encourage the exchange of experiences.

Another approach to speeding up policy making and injecting greater flexibility to accommodate the speed of the digital economy is to avoid overly specific regulations and instead opt for more open regulation and broader guiding principles. This approach was taken in the transition of the Internet Assigned Numbers Authority (IANA) function (NTIA, 2014 [41] ) or OECD's promulgation of Council Recommendations ("soft law"), such as the Internet policy making principles. Consideration could also be given to the delegation of certain policies to private entities, subject to public review, and the use of public-private partnerships where governments can leverage the agility (and resources) of the private sector.

Policy itself can also make greater use of growing data flows and big data analytics to reduce the gap between policies and the evidence on which they rest. For example, new private sources of data can be used to generate early estimates of measures, improve estimates in other areas, or develop new proxy measures for aspects that are not adequately covered by official statistics, presenting opportunities for innovation by national statistical offices. More broadly, digital technologies and the active collection of data holds promise for the improvement of policy design, implementation, evaluation and enforcement (Meeker, 2018 ${ }_{[33]}$ ).

\section{B. Ownership, Assets and Economic Value}

Thanks to digital coding and intermediation, the vectors of scale, scope, and speed are being combined in many ways, often amplifying each other. These vectors provide competitive advantage and shift investment toward intangible sources of value many of which can be digitised. These intangibles, like software and data are increasingly combined with traditional tangible investments in tools, machinery, autos and buildings - creating new assets that can be continually adapted to fit changing conditions and exploit new opportunities.

A key element of the digital transformation of capital equipment and structures is the flow of data generated through embedded sensors that monitor performance (e.g., jet engines, water meters). The exchange of data allows the continuous improvement of the asset through feedback loops and machine learning as well as the provision of new services based on the analysis of the data streams. Another change to the nature of investment in tangible capital is the advent of platforms that connect owners of capital (e.g. cars, real estate or computing) to users. This facilitates more productive utilisation of capital as well as the provision of new services.

\section{Intangible assets and the new sources of value creation}

Since the mid-2000s, a growing share of business investment consists of intangible, knowledge-based capital (KBC) rather than traditional tangible capital (OECD, 2013 ${ }_{[42]}$ ). As demonstrated first by Corrado, Hulten and Sichel (Corrado, Hulten and Sichel, 2006 [43]), investments in intangible assets have grown quickly and now match or exceed traditional capital in a number of developed economies (Figure 2). As they are intangible, assets in the form of know-how, business processes, or organisational structures can be wholly or partially digitised, raising new questions around the nature of this investment and the policies that incentivise their development and acquisition as opposed to policies for 
traditional, tangible investment. For example, many intangible assets are non-rivalrous and hence do not lose value (and may in fact gain value) (Amazon, 2014 [26]) if used by others and they can be replicated and shared easily and with near zero marginal cost. On the other hand, many involve proprietary interests that are at least in part protected by limited access, contracts, and/or intellectual property or privacy rules (Goodridge, Haskel and Wallis, $2014_{[44]}$ ), and thus their diffusion can be restricted and controlled to varying degrees. This is in contrast to traditional forms of capital that are available with few, if any, restrictions.

Figure 2. Business investment in fixed and knowledge-based capital, 2015

As a percentage of business sector gross value added

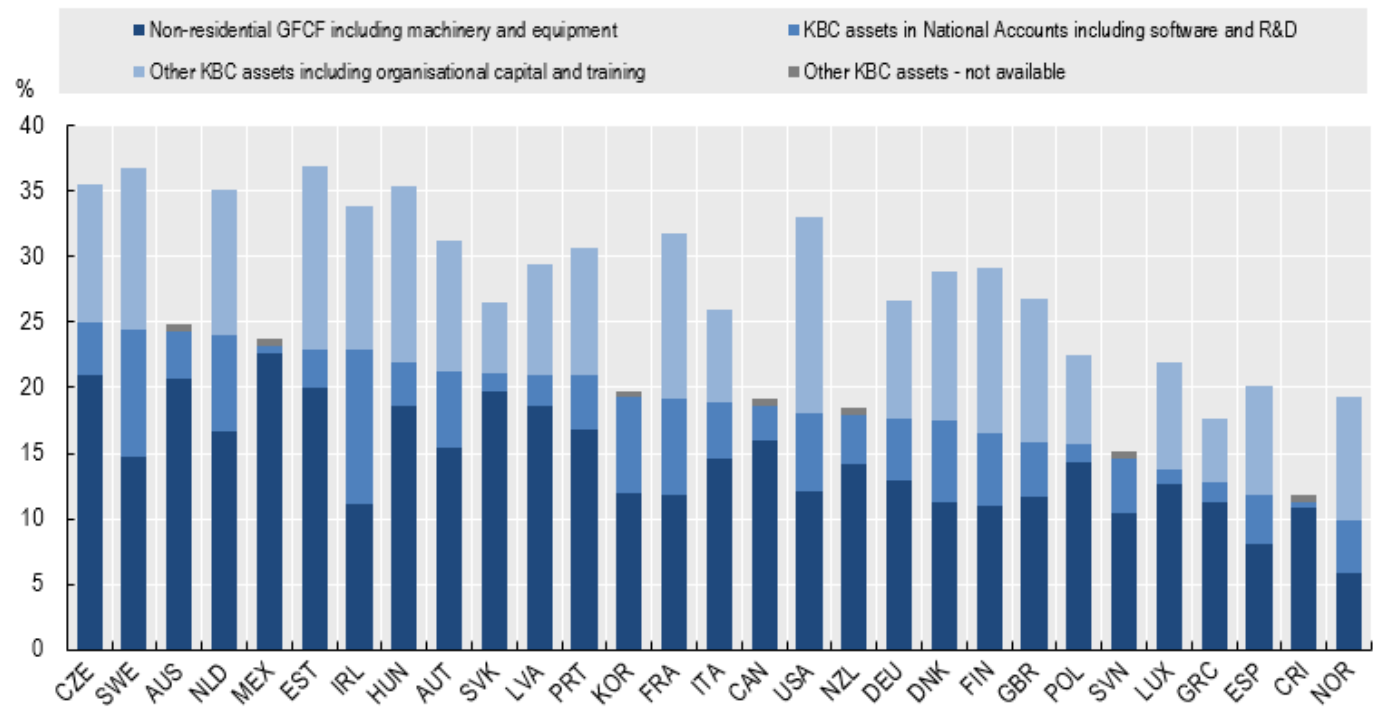

Note: See details in endnote [4]

Source: (OECD, 2017 $[46])$

In many cases, equipment providers sell services deriving from their assets either instead or in addition to selling their capital goods. This reframes the ownership and use of the asset, and changes the source of value creation. For example, firms such as Rolls Royce and John Deere use sensors embedded in their tangible capital goods (jet engines, tractors) to send data about the performance of the equipment and the conditions of its operation (OECD, 2017 $[45])$. This enables these companies to provide ancillary services to their clients, in some cases transforming a simple sale into a contract for a larger package of services, often tied to a long-term lease.

In addition to the shift from goods to goods bundled with services, there is a shift from goods to services which is particularly pronounced in the Information Technology (IT) sector. In that sector, "the cloud" and high-speed networks enable firms to acquire IT services rather than purchase equipment outright (Van Ark, B., 2016 $\left.{ }_{[47]}\right)$. Cloud platforms enjoy economies of scale and scope, along with the ability to balance demand across regions and users. They can provide users with scale on demand, lowering the fixed costs of starting a business. Along with the availability of open source software, this has been credited with vastly decreasing the cost of Internet start-ups and the associated need for early capital, thereby spurring innovation and lowering barriers to entrepreneurship (The Economist, 2016[48]). As cloud providers continuously upgrade their equipment, software and offerings (e.g. some now include Artificial Intelligence (AI) services), cloud services 
may allow users to avoid the problem of transitioning from legacy environments (Toffler, $\left.1980_{[2]}\right)$.

Another variant of how data flows enable the emergence of new business models occurs where the factory floor is digitised and the production process can incorporate a "digital twin" that operates in parallel to the material process (OECD, 2017 $\left.{ }_{[49]}\right)$. This enables the collection and analysis of data that improves the performance of the production process. Plant operators can optimise the control of the plant to increase efficiency, make informed decisions regarding trade-offs between performance and durability, assign loads and lineups through time, perform the right maintenance tasks at the ideal moment, head off costly problems before they occur, and explore the future through simulations.

"Digital twins" also allow for the adoption of new business models whereby a firm which had previously sold physical capital or consumer durables now sells a service based on the product's use over time. While the model may vary, the key point is that a firm maintains at least some form of responsibility - helping to predict, inform, and warn an enterprise against incurring unnecessary costs or wasting resources - throughout the entire lifecycle of a capital good. These dynamics suggest that the value of asset ownership and manufacture may increasingly rest with the data generated as a result of its use.

Digital technology also facilitates the sharing of physical assets over time, notably through platforms (see below). This "sharing" allows individuals, among others, to increase the utility (and presumably the value) of their real estate, vehicles and even of smaller capital purchases such as garden equipment and tools.

\section{Examples of policy implications}

The shifts in both the nature and use of capital have implications for policies directed at encouraging investment such as tax incentives, accounting rules for (accelerated) depreciation and subsidies for domestic or foreign direct investment as well as general measures of investment (OECD, 2013 $\left.{ }_{[42]}\right)$. In many cases, such incentives were designed for tangible, physical capital residing in specific jurisdictions, not for intangibles or for investment that has been made part of a service that may be purchased from abroad. For example, current concerns about a decline in investment may be assuaged somewhat by the only partially measured growth of knowledge-based capital.

The rise of sharing platforms (including cloud computing) may broaden the use of capital and increase its efficiency as idle time falls, thereby reducing the need for new investments. For example, roughly one-third of US gross fixed capital investment currently consists of ICT (OECD, 2015 $[50])$; as businesses increasingly purchase computing and software services from the cloud, this share should fall. An International Data Corporation (IDC) report estimates that for every euro spent on the cloud (software as a service) it replaces EUR 2.3 previously spent on hardware, software and services (European Commission, $2015_{[51]}$ ). Furthermore, increasing substitution of ownership by rental of physical capital may affect the measurement of economic performance (e.g. measures of investment and productivity) and make it more difficult to assign where value is added. Not least, as asset use becomes increasingly governed by licensing or rental arrangements, consumers may lack a full understanding of their rights and limitations in relation to usage or consumption.

Many existing policies for investment are also predicated on the notion of rewarding the investor, often presumed to be the owner, and thus stimulate the take-up of technology. The embedding of capital into a service (and its accounting as a current expenditure), or vice versa, may decouple this link. This may be further complicated when the owner and user 
of capital, and/or a provider of the service, are situated in different countries. This has implications for the type of policies used to foster domestic investment.

The increasing entanglement of digital services with physical goods has implications for trade policy, which traditionally makes a distinction between trade in goods (e.g. a computer) and services (software as a service, or the cloud). Increasingly, cross-border data flows allow goods to be traded as a complement of a service package and vice versa. This may result in a rise in the trade of services delivered via the Internet and could contribute to a decline in the share of trade of goods (OECD, 2017 ${ }_{[52]}$ ) (The World Bank, 2017 ${ }_{[53]}$ ). Moreover, the advent of digital twins of products, discussed above, coupled with 3D printing may require trade rules to take into account the possibility of trading such products as either a digital "engineering service" or a manufactured physical good. Cross-border flows related to the ownership of intellectual property assets in different countries, along with flows of data across borders and between actors pose additional measurement challenges that are linked to intangibles and the sources of value creation. These flows, which are likely to grow, underscore concerns about restrictions placed on cross-border data flows.

Data being gathered by a firm may be used to improve its products or services to final consumers; or it may be sold off to generate an independent revenue stream. From the tax policy perspective, it is unclear whether and how value should be attributed to raw data, and whether value and taxable profit should be allocated to the jurisdictions in which the data originates.

Another important policy implication flowing from the increasingly intangible nature of capital and production more generally is the importance of intellectual property rights (IPR) policies. IPR policies reflect fundamental international expectations that apply to most economic activities involving inventions, designs, branding, creative works, and confidential business information. Here also, small firms must sometimes face the high costs of locating and evaluating patents, negotiating licenses, and in protecting the benefits they derive from their own intellectual property. Many governments and IP offices have sought to offset these costs through specific programmes aimed at helping small firms with intellectual property and some have even developed sovereign patents funds as a method of reducing the costs for SMEs, e.g. in gaining licenses and access (CIGI, 2017 ${ }_{[54]}$ ).

\section{Relationships, Markets and Ecosystems}

A general-purpose infrastructure, the Internet was a revolutionary departure from analogue communications such as telephony and broadcasting. Before the Internet, there was no common infrastructure to connect users, digital assets, and physical objects. As noted below, the Internet's "end-to-end" principle means that anyone user can connect to any other user. Hence, while digitisation changes the nature of products, the Internet has enabled changes in the formation, maintenance and nature of relationships.

First, the Internet has made digital products accessible and usable worldwide while radically reducing the costs of communicating and transacting. This has enabled a shift in production to extended supply chains and global value chains (OECD, 2013 $3_{[55]}$ - or to "clusters," since complementary relationships in the digital environment can extend in multiple directions. This combined with the fact that digital products can hold and convey diverse forms of information - addresses, code, content, metadata - has vastly expanded the potential for interoperation and data-sharing among individuals, businesses, organisations, and governments wherever they are located. This not only empowers 
bilateral relationships, it also supports and enhances the operation of markets. Markets become larger and more informed, efficient, and complete, and can be managed as massive private enterprises that bring disparate interests and objects together on technologically sophisticated platforms.

Similarly, networked digital technology enables the design and configuration of specialpurpose networks, whether for social interaction or to create new knowledge. Ad hoc networks can be designed and configured using simple tools such as a mailing list or website without having to deal with a carrier or other intermediary. Well-designed digital interactions can quickly exchange large amounts of structured information, thereby disintermediating functions previously performed by specialised experts. For example, airlines now design their websites to allow customers to plan their own trips, reducing the need for professional travel agents. The new relationship, enhanced through data collection, can sustain and nurture long-term relationships which in turn further reduce the costs of individual transactions (e.g. credit card information or addresses are stored) and "churn." While the virtual nature of digital connections may erode confidence in some transactions, online reputation systems, real-time fraud analysis and other big-data analytics, and distributed ledgers (block chain) can also engender and increase trust.

\section{Transformation of space}

The ubiquity of the Internet and the ease of moving intangible sources of value, especially those in digital form, makes it more difficult to ascribe a fixed location to value creation, product origin, "permanent establishment," or the "nexus" of an activity. For example, data can be captured, encrypted, transformed and stored indefinitely in multiple locations anywhere on earth, decoupling value from a specific geographic location and creating opportunities for regulatory arbitrage (i.e. taking advantage of differences between national rules). Digitised information can be rapidly transported over long distances without deterioration in quality, enabling cross-border tradability of services and reducing the need for physical collocation. The ease with which national boundaries can be crossed without immediate detection or consequence may reduce the role of physical location and proximity as an organising principle for some economic and social activity (OECD, 2019 ${ }_{[56]}$ ).

Conversely, digital transformation may increase the importance of particular spaces. GPS and geo-location link information to, and derive data from, specific locations, enabling the growth of localised information. Whether contained in maps or messages, this information dramatically decreases search costs whether it be for a place, a person, specific interests, or places to avoid. Thus, it may highlight objects, activities, businesses, etc., that were previously unknown to users.

Another example of how the digital transformation alters space is through economies of agglomeration. In a digital environment where codified knowledge is easily shared, tacit knowledge embedded in individuals becomes relatively more valuable. The accumulation and mixing of tacit knowledge or complementary skills (e.g. coding, finance, managerial know-how) in specific places has contributed to the growing importance of cities or agglomerations like Silicon Valley that have become magnets for highly specialised workers and the firms that seek them. This localises innovative and productive economic activity and boosts cities and regions as engines of economic growth and political forces.

\section{Examples of policy implications}

The ability of intangible assets and data to be stored in any location challenges policies that rely on geographic location, e.g. geographic nexus for assessing tax, rules of origin in trade 
policy, definition of markets for competition policy, education funding defined by districts, labour regulations formulated around employees and employers in a particular place (e.g. office, factory), which can be rendered less meaningful and effective.

To address this, one option may be to shift the focus to the geographic location where the value is diffused or used (value consumption). This shift from creation to use may have implications for corporate and labour taxation, trade and the rules of origin, as well as education policy and its focus on specific schools or districts. More generally, the erosion of sovereign control over some activities may incite a shift in national policies towards those activities that are geographically bound such as tourist attractions, natural endowments, agriculture and even place a premium on geographically differentiated products (e.g. Tennessee whiskey or Gien china).

The geography of economic activity in a digital environment was assumed to become "flat" (Friedman, 2005 ${ }_{[57]}$ ) and digital networks were expected to reduce the appeal of cities and support rural development. This has not happened; specific urban areas or agglomerations like Silicon Valley or Shenzhen increasingly attract and concentrate complementary skills and continue to drive overall economic growth. This "spikey" phenomenon supports the growth of policies that seek to develop or nurture clusters that support investments and activities where tacit knowledge and interpersonal exchange is important, but raises issues of geographic equity and spreading the benefits of growth.

More generally, the diversity and density of activities found in cities put them at the forefront of digital policy experimentation as they strive to become "smart" by deploying sensors, re-engineering infrastructure and using the wisdom of the crowds (OECD, 2015 $\left.5_{[5]}\right)$. This has led to new growth in digitally-enabled trade in services that is inherently local (such as accommodation and public transport) and fuelled by geo-location data, which is especially dense in cities. Cities may therefore become the operating level from which valuable policy lessons can be learned and experimentation observed.

As described above and below, digital transformation and the general lowering of transaction costs allow greater tailoring, a granular approach, a reduced need for hierarchies to process information and co-ordinate activities, and a reconfiguration of communities and organisations that is less geographically bound. The implications for nations are that they sit uneasily between borderless, global connectivity and the synergistic nodes that form at the local level (Negroponte, $1995_{[58]}$ ).

The phenomenon of entities that operate at a global scale and erode the efficacy of geographically-bound sovereign states has a long history (Vernon, 1971 ${ }_{[59]}$ ), but the digital transformation vastly broadens its effects, threatening to weaken the state's ability to develop and enforce domestic policies. As the scourge of child pornography illustrates, the nature of the Internet makes it difficult to trace activity or completely block access to illegal material, services or activities. The rise of geo-location data (e.g. tracking devices like RFID tags), Internet protocol address filtering and other technologies have provided some fixes but these are often clumsy and only partially successful (Bezos, 1997[28]). The implications are wide ranging across policy areas from trade, to health policy and the potential access to illegal drugs, to tax, where aggressive tax management has led to tax base erosion and profit shifting across jurisdictions.

As the Internet Governance debate over the governance of domain names and fears of politically motivated fragmentation of the Internet continue, it should be recognised that greater sovereign control imposes costs on the functioning of the system, weakening the economic benefits (network effects) and free flow of information that is critical to 
innovation. It is important to foster solutions that preserve the open architecture of the system and limit sovereign control to important legitimate issues that cannot be resolved through interoperability agreements. Examples of such agreements between policy regimes include the agreement between the US and Europe on flows of personal data, first agreed to as a "U.S.-EU Safe Harbor" framework, and revised as the "EU-U.S. Privacy Shield." Non-digital examples include the bilateral agreement on taxation and agreements on the termination of international phone calls. More generally, cross-border data flows and the scaling of global digital services, may suggest a need for further agreements on access to networks, data portability and flows, and digital security.

\section{Empowerment of the Edges}

Thirty years ago networks were specialised by the type of service they provided (e.g. switched telephony for voice and broadcasting for video). The intelligence of the network was at the centre (a command and control model) and the end user had a "dumb" device like a simple phone or a TV. The "end-to-end" principle that is at the heart of the Internet protocol $^{5}$ has moved the intelligence of the network from the centre to the edges where "application-specific functions reside in the end hosts of a network rather than in intermediary nodes" (Saltzer, Reed and Clark, 1984 ${ }_{[60]}$ ) (Estrin, 2015 [29]). Furthermore, the Internet has led to a convergence of these separate services, along with text and data services such as the Web and email.

Declining costs of communication and information processing, along with the functional empowerment of the edges, encourage individual users to communicate to multiple parties, in effect setting up new networks built on an existing network. Thus many-to-many communications can sidestep and partially supplant hierarchical structures that channel and process information up and down a chain of command. Just as the industrial revolution led to the invention of the modern limited liability corporation, so might the digital era lead to new, flexible forms of organisation, configured from an array of quasi-independent small enterprises and individuals. Decomposition into smaller components of value, combined in ways that create greater value may reduce the distinction between economic categories such as business and consumer, work and leisure and home and office.

This functional decentralisation and diffusion leads to the empowerment and broadening of networks, markets, and communities. It affects where power and influence reside as well as how people interact with each other. It erodes the influence of "one-to-many" institutions such as newspapers, broadcast TV and radio, and governments. The rise of Internet-enabled "many-to-many" communications allows individuals to become publishers, journalists and pundits, fragmenting control over information. Disenfranchised groups, minorities, the young and old, and fringe groups can seek out like-minded people, inspire a following, or exploit the "wisdom of the crowd." Remote communities can become involved in wider networks and engage in economic activity on a global scale. Entrepreneurs are provided with a wide range of tools to connect to potential clients, funders and suppliers around the world. However, this shift of power to a wider array of players and ad hoc networks may fragment the political process and any sense of a collective identity.

The rise of "many-to-many" and the reconfiguration of how people interact affects the sense of community that used to be geographically based and largely local (neighbourhoods, congregations, schools, teams). The ability to connect with anyone anywhere on the Internet is enhanced by platforms that lower the barriers to finding likeminded thinkers, creating communities uncoupled from geographical location or jurisdiction. Algorithms that accurately predict preferences based on past behaviour, 
patterns and choices may produce a self-selection bias that reinforces existing relationships and prejudices, resulting in what some call an "echo chamber." At the same time, the ability to learn about other communities can fuel exploration and migration as the ambitious can see how others live, communicate with family and members of diasporas, and gather essential information about a location before moving (Kozlowska, 2015 [61] ).

The empowerment of the edges can offer new opportunities for individuals, communities and regions to connect to the global community, including in offering local products and services on-line and creating new economic opportunities. Mobile telephony in particular has been used intensively in a number of inclusive innovation initiatives that aim at improving the welfare of lower-income and excluded groups in developing countries. A famous example includes mPesa, which has provided millions of Kenyans with access to basic banking services.

More broadly, the "empowered edge" enables ubiquitous computing that drastically reduces information asymmetries that previously existed. This allows consumers to find better prices for products (as well as identify better quality products), it facilitates access to key goods and services, e.g. mobility and accommodation, and at the best price. Digital technologies can be a significant driver of improved services to vulnerable groups in society (Mickoleit, 2014 $[62]$ ). For example, opportunities to file taxes and apply for public support online have made procedures more convenient, benefitting in particular individuals located in remote areas and lower-income and excluded groups who rely on public support. Technologies can enable disadvantaged individuals and groups to connect and co-operate. For example, the Danish OnlineTele is a web-based portal that offers a range of services to vulnerable elderly people, including video communications (one-on-one, one-to-many, many-to-many) that can be used to deliver remote care.

Although many-to-many interactions now take place over online platforms, the new centres in cyberspace, the Internet has long enabled one-to-one flows of information that bypass third-party intermediaries altogether (e.g. SMTP email, hyperlinks on the Web). A more recent example is the emergence of distributed ledger technology (block chain), an open shared and distributed public record of information that cannot be altered and is therefore trusted by all participants (OECD, 2016 $\left.6_{[63]}\right)$.

\section{Examples of policy implications}

As the intelligence of the edges expands, empowered first by the personal computer, then the smartphone, and soon the "Internet of Things", end users take on roles and responsibilities that used to reside in the centre of the network (e.g. including privacy and security). The essence of "empowered edges" is the ability to exchange information from any one endpoint. This results in massive data flows, as well as data about these data flows (metadata). The growing velocity, variety and volume of data change its nature and make it a factor of production akin to labour and capital. These torrents of data and big data analytics open up huge new economic and social opportunities as well as important policy questions regarding who owns, controls and has the right to collect this data that become central to almost all policy domains. Protecting the privacy and security of the data becomes a critical issue that now extends across all sectors of the economy. More generally, every part of the economy and society needs to be aware of the changing nature of data (growth in volume, velocity and variety) and the need to practice "digital hygiene" (e.g. be aware of how personal data is used, engage in good security practices and be cognisant of the negative aspects of being always connected). 
At the same time, the resulting reduction in one-to-many mass communication may make it difficult to generate support for public policy goals that require collective action (e.g. climate change) and affect the ability to monitor the diffusion of inaccurate or harmful information ("fake news"). Many of the emerging and influential one-to-many voices include institutions and individuals, rather than simply organisations that produce media content. More positively, the empowerment of the edges can fuel debate, empower more voices and may strengthen democracy, to which end policies should preserve this "end-toend" capability for exchanging information with any other user. Some policies that were previously directed towards mass-media outlets may now need to take into account of the role of online platforms, as these enable and shape many-to-many as well as new forms of one-to-many communication. Legislative solutions are difficult to envisage but might include, for example, the prevention of censorship or requirements for transparency in news reporting. As in broadcasting, the creation and delivery of news and information deemed to be in the public interest may need to be promoted as a public service. Already, some philanthropies support investigative journalism ${ }^{6}$, and platforms have sought to develop means to identify and combat fake news (BBC, 2017 $[64]$ ).

Along with the loss of place, the creation of communities that are not grounded in geography may weaken the collective sense of belonging to specific places such as regions or countries or cultures, and hence limit collective decisions at that level. Conversely, these self-constructed like-minded communities that span geography may strengthen global movements, as well as the attachment to very local communities through improved information sharing on a micro-level. This global-local shift could strengthen the policy role of non-state actors such as non-governmental organisations and individual champions - as well as rogue groups who wish to operate outside of existing laws. There may be a need to assess the merits of bolstering policy development and execution at local and global extremes as opposed to the traditional reliance on national or federal systems.

The implementation of public policies previously dependent upon large centralised services such as private human resources departments may need to adapt to, and benefit from, the reduced transaction costs enabled by the Internet. This may entail directly interacting with the edges - small units and individuals - possibly through platforms run by public bodies, non-profit organisations or private firms. This collective intelligence can be used to achieve policy goals like reducing water consumption, targeting road maintenance or engaging in large scale science projects. While this detailed level of engagement would have been impossible to imagine in earlier times, large platforms make it feasible in the digital era, along with the ability to finely and precisely target policies to specific groups (Mardiste, 2016 $6_{[65]}$ ) (Mercado, 2017[66]).

Equally, the power of the edges may erode the need for the centralised implementation of regulatory functions. For example, the use of new technologies like block chain (digital distributed ledgers) may eliminate the need for some existing regulatory functions aimed to authenticate, certify, or track transactions. As the block chain is transparent, immutable and subject to constant oversight, participants are able to directly transfer value without a centralised validating mechanism, by-passing trusted institutional intermediaries like banks. At the same time, it poses new challenges such as how to enforce law in the absence of any intermediary or how, and to whom, to impute legal liability for torts caused by block chain-based systems (OECD, 2017 $\left.{ }_{[67]}\right)$. Similarly, intelligent edges can engage in peer-topeer exchanges of digital content (from songs to 3D printing models) with the help of simple distributed technologies such as attachments to e-mails, challenging the enforcement of intellectual property rights and other laws. 
The implications of the empowerment of the edges and the decentralisation it promotes are becoming topical across a range of policy areas. Labour and social policies such as training, health insurance, working conditions or collective bargaining are in many countries designed to be implemented by large firms and organisations, but the rise of the "freelance" or "gig" economy where work is organised through intermediary platforms like Uber or Mechanical Turk points to different models of organisation. On the one hand, it allows for much greater flexibility and can help tap into underutilised talent pools (older people, foreign workers). It also enables smaller firms to take advantage of outsourcing and offshoring opportunities that were previously reserved for larger companies. On the other hand, it compels reconsideration of how to achieve the relevant public policy goals such as worker training, retirement, health care, and minimum labour standards. Moreover, it encourages mobility, roaming and nomadic habits since work can happen anywhere. This raises issues of how and where labour taxes should be paid and where benefits should be drawn. More generally, as individuals are empowered to work, consume and be an entrepreneur via platforms, the distinction between what constitutes a worker, business or consumer blurs (U.S. Department of Commerce, 2017 $[31]$ ).

\section{The Rise of Platforms and Ecosystems}

While the shift of intelligence from the centre to the edges promotes decentralisation, new forms of intermediation are arising. These engage and often empower end users, providing them with e-commerce, content distribution, search and storage services, and social networks, to name a few examples. These forms of intermediation are typically proprietary but can be found on the public Internet. They are often provided through online platforms - "algorithm-enabled 'cyber places' where actors can act or transact; hence they are more than matchmaking or markets", they can also constitute a social community (Kennedy and Zysman, 2016 $\left.{ }_{[68]}\right)$. Online platforms promote decentralisation by lowering the barriers to participation, often furthering empowering the edges. For example, platforms like Amazon Marketplace and MercadoLibre's MercadoShops lower the cost of starting a new business by providing fast, easy ways to set up e-businesses, reach customers and fulfil orders, thereby promoting entrepreneurship. Facebook hosts more than 60 million business websites at no charge, although it earns advertising revenue in doing so. Yet platforms also concentrate control into a proprietary service that owns the underlying technology, sets the ground rules for interaction, and collects data from and about users. Many platforms benefit from both network effects and two-sided business models which have led to a leading position in their respective markets, resulting in no changes in the top-five platforms over the past 5 years. Many of the leading platforms have been active in mergers and acquisitions which have both allowed them to expand the scope of their eco-systems and acquire expertise.

An online platform can be described as a digital service that facilitates interactions between two or more distinct but interdependent sets of users (whether firms or individuals) who interact through the service via the Internet. For example, online video sharing services are platforms that can have at least three sets of users who interact in multiple directions. The users include those who upload videos, those who watch them, and those who pay the platform to place advertisements. Interactions flow from video uploaders and advertisers to video consumers, but they also flow from consumers back to the uploaders in the form of comments and, in the case of other platforms, in the form of ratings. In addition, they can flow from consumers to other consumers (again in the form of comments and feedback). 
Digital ecosystems are combinations of applications, operating systems, platforms, and/or hardware that interoperate in certain ways to enhance the user experience and/or aggregate data (e.g. Amazon's Fire tablets, the Fire OS fork of the Android operating system, and interoperable apps and ebooks; Apple's iPhones and iPads, their iOS operating system, and interoperable apps from the Apple App Store). Ecosystems can offer users ease of use, convenience, and a familiar look and feel with which they may grow comfortable, but they may also limit interoperability outside the ecosystem. This may effectively raise users' switching costs if and when a better product comes along, thereby helping incumbents to fend off market entrants - and competition from one another.

\section{Examples of policy implications}

Digitally enabled markets are now quickly gaining prominence, combining unprecedented scale, scope, and speed with enhanced social and economic resources, structures, and activities - and accommodating everything from high-frequency trading to crowd funding for loans to housecleaning to the sale of stolen identities. The ebb and flow from decentralisation to concentration and the rise and occasional fall of large intermediaries have implications for many policy areas ranging from the provision of public services, to competition, labour and tax policy. For example, should the "public interest" obligations of existing intermediaries (e.g., broadcasters) be transferred or assigned to emerging services and platforms that provide news and other programming? Or do new technologies negate the need? Telecommunication carriers are required to provide emergency services (e.g. 911 in the US or 18 in France), but should platforms that have messaging applications or voice-over IP services have a similar obligation? Banks are often required by public policy to filter transactions for suspicious activity like money laundering; should new fintech services have similar obligations?

The role of public services is being questioned in some areas. Digital giants are assuming functions performed by the post office, public broadcasting, civil defence agencies, libraries, and public meeting places. They provide basic "public" services such as maps, mail, messaging, emergency messages and employment offers. This suggests re-thinking how existing public services should be adapted where the rationale for public intervention may have eroded. In some cases, governments may consider developing or supporting platforms that meet specific public needs, such as those developed by Estonia for health, voting and taxes (e-estonia, 2018 $\left.8_{[69]}\right)$. After decades of a "light regulatory touch" there has a recent trend towards imposing more responsibility on platforms. While inevitable, these rules need to be transparent, avoid imposing impossible or ill-defined responsibilities and require careful consideration to avoid unintended outcomes that could reduce innovation and raise barriers to entry.

In some countries, commercial platforms have started collaborating with public authorities in sharing data on income to facilitate tax collection, by directly collecting taxes, such as lodging taxes (Airbnb's agreements with over 250 jurisdictions in the US) (Airbnb, $2017_{[70]}$ ), or by sharing relevant data with tax authorities (Uber in Estonia) (Mardiste, 2016[65]).

Digital platforms can also raise issues of equal access and market concentration. As is frequently the case, this debate first emerged in the ICT sector itself in the discussion of "network neutrality" and the access to established communications networks by other services. It has evolved to encompass services offered by a handful of the most valuable companies in the world with their scale and scope reinforced by interoperating applications that collectively constitute not just platforms but ecosystems. 
In the case of social networks, users interact by contributing content to various platforms (e.g., Facebook, Twitter), which enables the companies to collect data. Because users volunteer the data, it is not priced and thus escapes the tax net, yet the data clearly has a value to social network companies. The accumulation of user data, the size of the subscriber base, and the ability to learn from vast amounts of user data - and to add value to users from that learning - may help large platforms to supplement network effects and achieve a strong, possibly enduring position in the market. Nevertheless, while online platforms sometimes raise competition concerns and frequently disrupt the status quo, their widespread use reflects their innovations, utility, and value to consumers.

New digital business models that compete with traditionally regulated enterprises compel policy makers to rethink whether existing regulation is well suited to the new environment and, if so, how best to engage the new entrants. This requires an assessment of the relevant market that takes into account its evolving characteristics and the dynamics of digital transformation. Identifying competitive distortions and addressing them in a way that preserves the benefits of new technologies can be a difficult sector-by-sector endeavour. Although some conduct by online platforms may appear to be anticompetitive and deserves scrutiny, policy makers should also be wary of oversimplified or misleading calls from incumbent players to "level the playing field" that merely seek to tilt the advantage back to themselves, particularly when their access to, and expertise in, the policy process dwarfs that of the entrants.

At a minimum, this requires that policy makers and regulators have technical and market expertise, and in fact many regulatory agencies now employ staff with such expertise, or are in the process of recruiting. But acquiring and retaining qualified staff may require adjusting civil service employment rules and granting regulatory agencies the ability to make working conditions sufficiently attractive and competitive. 


\section{Conclusion}

The digital transformation is exceptional in its velocity and breadth - characteristics that challenge policy making in distinctive ways. The transformative effects move faster than the policy-making process. As the discussion in this paper illustrates, the digital transformation is not a simple phenomenon but a complex range of continually unfolding, interrelated, and often unpredictable developments. In governments with a broad set of specialised competencies, adaptation may become an exercise in managing divergent approaches across administrations which may each have their own culture, leadership, mission, and methodologies. In an era of hyper-connectivity, the challenge is to avoid wellintended policies in one area conflicting with policy objectives in another. For example, privacy protection that thwarts tracking a disease or ride sharing restrictions that cut off job prospects for those seeking work. What is needed is a holistic, whole-of-government approach that is better positioned to weigh the trade-offs and ensure coherence across a range of policy objectives. This is easier said than done, but providing the tools to develop such an approach is the objective of OECD's "Going Digital" project.

The transformation also challenges traditional thinking on how economic and social activities are most effectively organised and performed. It is not simply a question of whether private enterprises, public institutions, or non-profit organisations are best suited to a particular task. The Internet and the Web as standards-based public platforms enable a wide range of networked activities that serve shared interests; examples include consensus standards, open source software, research collaboration, and third-party review. Simple bilateral transactions and relationships can become richer and more interactive; markets take on new scope, scale, and speed, as do non-market transactions and person-to-person interactions. Instead of a binary choice between public and private, digitalisation provides for gradations, hybrids, and variants. It allows for continual fine-tuning of access, control, participation and function - in contrast to the stable and embedded architectures of the physical world or, for that matter, the evolved institutions of advanced economies.

While digital transformation has been underway for several decades, it will continue to expand and evolve in unexpected ways, and policy makers will therefore continue to be challenged in their approaches to policy making. Sharing of evolving good practices, experimentation with new approaches and policies, and an ongoing reflection on new policy approaches will therefore be important. The OECD's Going Digital project aims to support policymakers in this process. 


\section{Annex}

Table A .1. Checklist for Policy Development in the Digital Era

$\begin{array}{ll}\text { Scale without } & \text { Do your size-based (e.g. SME or de minimis) policies account for small } \\ \text { Mass } & \text { firms with large revenues and extended (global) reach? }\end{array}$

Panoramic Scope Do your competition policies adequately address the ability to scale quickly due to low transaction costs and in many cases network effects as well as reinforcing data flows that may make create a barrier to entry?

Do your policies (e.g. trade) that make a distinction between manufacturing and services still apply to digitally enabled products?

Are your policies neutral in terms of treatment of traditional firms as opposed to digitally enabled firms who may be a new entrant with a new business model?

Is your current administrative structure well-aligned with the transversal demands of digital scope that frequently crosses policy domains?

Speed: dynamics of time

To facilitate the exploitation of economies of scope and accelerate the policy making have you considered providing some regulatory relief to firms by creating spaces for policy experimentation (e.g. sand boxes, policy labs)?

Is there scope for replacing overly specific regulations that may be quickly obsolete with more general principles that allow greater flexibility?

Have you considered how best to use new "big data" analytics to improve the design, implementation and evaluation of policies on a continuous basis?

Intangible assets

and new sources

Do your policies "follow the data" and make provisions for who owns the data, has control over it and is accountable for its stewardship?

Transformation of Do your policies that incentivise investment account for purchase of Space capital services as a current expenditure as opposed to the outright purchase of the capital goods?

Do your statistical measures adequately capture flows (including cross border) of digitally delivered services (e.g. cloud computing) or payments for use of intellectual property?

Do your policies that are based on geographic concepts like nexus, country of origin or defined markets take into account the ability of digitally enabled firms to provide products and services with little or no physical presence?

Have you considered policy initiatives that directly connect value creation to a place such as tourism, natural resources or geographically branded products (e.g. Tennessee whisky, Parma ham)? 
Are you exploiting the growth of geolocation data to develop smart cities which in turn can root value creation locally and can provide valuable lessons for policy making across levels of government?

Empowerment of Have you developed policies that exploit the ability to more accurately the Edges target policies to individuals, specific businesses or exact locales? Have you considered the use of block chain technologies that can augment government authentication and verification services?

Are you adapting, extending and making portable policies (e.g. labour, social policies) from institutions to individuals?

The Rise of Have you considered developing public platforms or partnering with Platforms and Ecosystems commercial platforms to deliver government services and execute public policies?

Have you sought to develop a cadre of civil servants with technical expertise that can help inform policy making and its implementation? 


\section{References}

Airbnb (2017), Tax agreements with 275 governments, https://www.airbnbcitizen.com/airbnbtax-facts/ (accessed on 15 October 2018).

Alphabet (2016), Annual Report, https://abc.xyz/investor/ (accessed on 20 December 2018).

Amazon (2016), Annual Report, http://phx.corporate-ir.net/phoenix.zhtml?c=97664\&p=irolreportsannual (accessed on 20 December 2018).

Amazon (2014), "Netflix \& AWS Lambda Case Study”, Amazon Web Services (AWS), https://aws.amazon.com/solutions/case-studies/netflix-and-aws-lambda/ (accessed on 12 October 2018).

American Auto Council (2016), US Economic Contributions, http://www.americanautocouncil.org/us-economic-contributions (accessed on 12 October 2018).

Anderson, J. and L. Rainie (17 april 2018), "The Future of Well-Being in a Tech-Saturated World", Pew Research Centre, http://www.pewinternet.org/2018/04/17/the-future-of-wellbeing-in-a-tech-saturated-world/ (accessed on 12 October 2018).

Andrews, D., C. Criscuolo and P. Gal (2016), The Best versus the Rest: The Global Productivity Slowdown, Divergence across Firms and the Role of Public Policy, OECD Publishing, http://dx.doi.org/10.1787/63629cc9-en.

Anthony, S. (15 July 2016), Kodak's Downfall Wasn't About Technology, https://hbr.org/2016/07/kodaks-downfall-wasnt-about-technology (accessed on 12 October 2018).

APEC (2015), APEC Privacy Framework, https://www.apec.org/Publications/2017/08/APECPrivacy-Framework-(2015) (accessed on 12 October 2018).

Apple (2016), Annual Report, https://investor.apple.com/investor-relations/financial-information/ (accessed on 21 December 2018).

BBC (15 January 2017), Facebook to roll out fake news tools in Germany, https://www.bbc.com/news/business-38631847 (accessed on 15 October 2018).

Bezos, J. (1997), Amazon.com - To our shareholders, http://media.corporateir.net/media files/irol/97/97664/reports/Shareholderletter97.pdf.

Blind, K. and B. Kahin (2017), Standards and the Global Economy, Cambridge: Cambridge University Press, http://dx.doi.org/10.1017/9781316416723.003. 
Brynjolfsson, E. et al. (2008), "Scale without Mass: Business Process Replication and Industry Dynamics", MIT Research Papers, http://ebusiness.mit.edu/research/papers/2008.09 Brynjolfsson_McAfee Sorell Zhu Scale\%2 0Without\%20Mass_285.pdf.

Burnham, K. (21 February 2014), "Facebook's WhatsApp Buy: 10 Staggering Stats”, Information Week, https://www.informationweek.com/software/social/facebooks-whatsapp-buy-10staggering-stats-/d/d-id/1113927 (accessed on 20 December 2018).

CHIPS Magazine (March 2017), About Grace Hopper, http://www.doncio.navy.mil/chips/ArticleDetails.aspx?ID=2265 (accessed on 15 October 2018).

Chui, M. and J. Manyika (2015), "Competition at the digital edge: 'Hyperscale' businesses", McKinsey Quaterly, https://www.mckinsey.com/industries/high-tech/our-insights/competitionat-the-digital-edge-hyperscale-businesses (accessed on 20 December 2018).

CIGI (2017), Understanding the Promise and Peril of Sovereign Patent Funds, https://www.cigionline.org/sites/default/files/documents/Policy\%20Brief\%20No.102web 0.pd $\underline{f}$.

Corrado, C., C. Hulten and D. Sichel (2006), "Intangible Capital and Economic Growth", Finance and Economics Discussion Series; Divisions of Research \& Statistics and Monetary Affairs; Federal Reserve Board, Washington, D.C. , http://www.federalreserve.gov/pubs/feds/2006/200624/200624pap.pdf.

Drake, W., V. Cerf and W. Kleinwächter (2016), "Internet Fragmentation: An Overview, Future of the Internet Initiative White Paper, World Economic forum.

eBay (2014), Micro-Multinations, Global Consumers, and the WTO, https://www.ebaymainstreet.com/sites/default/files/Micro-Multinationals_GlobalConsumers WTO Report 1.pdf.

e-estonia (2018), building blocks of e-setonia, https://e-estonia.com/solutions/ (accessed on 20 December 2018).

Estrin, J. (12 August 2015), Kodak's First Digital Moment, https://lens.blogs.nytimes.com/2015/08/12/kodaks-first-digital-moment/?_r=0 (accessed on 20 December 2018).

European Commission (2015), SMART 2013/0043 - Uptake of Cloud in Europe, https://ec.europa.eu/digital-single-market/en/news/final-report-study-smart-20130043-uptakecloud-europe (accessed on 20 December 2018).

Experts Exchange (2018), "Processing Power Compared", Hard Disk Drive Morph, https://pages.experts-exchange.com/processing-power-compared (accessed on 12 October 2018).

Facebook (2016), Annual Report, https://investor.fb.com/financials/?section=secfilings (accessed on 20 December 2018). 
Financial Conduct Authority (2015), Regulatory sandbox, https://www.fca.org.uk/firms/regulatory-sandbox (accessed on 15 October 2018).

Financial Times (2017), Publically traded companies by market capitalisation, http://Financial Times (2017) Publically traded companies by market capitalisation. https://markets.ft.com/data/dataarchive/ajax/fetchreport?reportCode=GMKT\&documentKey= 688_GMKT_160930. (accessed on 20 December 2018).

Fortune (2017), “Global 500”, Fortune, http://fortune.com/global500/list/ (accessed on 20 December 2018).

Friedman, T. (2005), The World Is Flat: A Brief History of the Twenty-first Century, Farrar, Straus and Giroux, New York.

German Federal Ministry for Economic Affairs and Energy (2018), Industrie 4.0, https://www.bmwi.de/Redaktion/EN/Dossier/industrie-40.html (accessed on 20 December 2018).

Goldfarb, A. and C. Tucker (2017), "DIGITAL ECONOMICS", NBER WORKING PAPER SERIES Working Paper 23684, http://www.nber.org/papers/w23684.pdf.

Goodridge, P., J. Haskel and G. Wallis (2014), Estimating UK investment in intangible assets and Intellectual Property Rights, https://assets.publishing.service.gov.uk/government/uploads/system/uploads/attachment data/ file/561709/Estimating-UK-Investment-intangible-assets-IP-Rights.pdf.

Kahin, B. (2016), Digitization and the Digital Economy, https://papers.ssrn.com/sol3/papers.cfm?abstract_id=2782906.

Kennedy, M. and J. Zysman (2016), "The Rise of the Platform Economy”, Issues in Science and Technology, Vol. 32/3.

Kimes, B. and H. Clark Jr. (1996), Standard Catalog of American Cars 1805-1942 (Third ed.), Krause Publications.

Kozlowska, H. (14 September 2015), "The most crucial item that migrants and refugees carry is a smartphone", Quartz, https://qz.com/500062/the-most-crucial-item-that-migrants-andrefugees-carry-is-a-smartphone/ (accessed on 15 October 2018).

Mardiste, D. (9 June 2016), "Embracing Uber, Estonia shows tax needn't be an issue", Reuters, http://www.reuters.com/article/us-estonia-uber/embracing-uber-estonia-shows-tax-neednt-bean-issue-idUSKCNOYV1PS (accessed on 15 October 2018).

Meeker, M. (2018), Internet Trends, http://www.kleinerperkins.com/perspectives/internet-trendsreport-2018 (accessed on 15 October 2018).

Meeker, M. (2017), Slide Share, http://www.slideshare.net/kleinerperkins/internet-trends-2017report (accessed on 12 October 2018). 
Mercado, D. (1 February 2017), 10 more states will now collect sales taxes from Amazon shoppers, http://www.cnbc.com/2017/02/01/10-more-states-will-now-collect-sales-taxesfrom-amazon.html (accessed on 15 October 2018).

Mickoleit, A. (2014), "Social Media Use by Governments: A Policy Primer to Discuss Trends, Identify Policy Opportunities and Guide Decision Makers", OECD Working Papers on Public Governance No 26, http://dx.doi.org/10.1787/5jxrcmghmk0s-en.

Negroponte, N. (1995), Being Digital, Alfred A. Knopf, New York.

NTIA (2014), "NTIA Announces Intent to Transition Key Internet Domain Name Functions", National Telecommunications and Information Administration, https://www.ntia.doc.gov/press-release/2014/ntia-announces-intent-transition-key-internetdomain-name-functions (accessed on 15 October 2018).

OECD (2019, forthcoming), BBVA big data on online credit card transactions and the patterns of domestic and cross-border e-commerce in Spain, OECD Publishing, Paris.

OECD (2017), Going Digital, http://www.oecd.org/going-digital/ (accessed on 12 October 2018).

OECD (2017), OECD Digital Economy Outlook 2017, OECD Publishing, Paris, http://dx.doi.org/10.1787/9789264276284-en.

OECD (2017), OECD Science, Technology and Industry Scoreboard 2017, OECD Publishing, Paris, http://dx.doi.org/10.1787/888933618688.

OECD (2017), OECD Science, Technology and Industry Scoreboard 2017: The digital transformation, OECD Publishing, Paris, http://dx.doi.org/10.1787/9789264268821-en.

OECD (2017), "The Future of Global Value Chains: Business as Usual or 'A New Normal"?", STI Policy Note, OECD Publishing, Paris, https://www.oecd.org/sti/ind/policy-note-future-ofglobal-value-chains.pdf.

OECD (2017), The Next Production Revolution: Implications for Governments and Business, OECD Publishing, Paris, http://dx.doi.org/10.1787/9789264271036-en.

OECD (2016), OECD Science, Technology and Innovation Outlook 2016, OECD Publishing, Paris, http://dx.doi.org/10.1787/sti_in_outlook-2016-en.

OECD (2015), Data-Driven Innovation: Big Data for Growth and Well-Being, OECD Publishing, Paris, http://dx.doi.org/10.1787/9789264229358-en.

OECD (2015), OECD Digital Economy Outlook 2015, OECD Publishing, Paris, http://dx.doi.org/10.1787/9789264232440-en.

OECD (2013), Interconnected Economies: Benefiting from Global Value Chains, OECD Publishing, Paris, https://doi.org/10.1787/9789264189560-en.

OECD (2013), Supporting Investment in Knowledge Capital, Growth and Innovation, OECD Publishing, Paris, https://doi.org/10.1787/9789264193307-en. 
OICA (2017), "World Motor Vehicle Production by Country and Type. USA Production for the year to date in quarter 4, 2016", OICA Correspondent's Survey, http://www.oica.net/wpcontent/uploads/By-country-2017.pdf.

Ostendorf, A. and K. König (2015), Tutorial: Laser in material nanoprocessing, https://www.ncbi.nlm.nih.gov/books/NBK321721/figure/oin_tutorial.F3/ (accessed on 20 December 2018).

Saltzer, J., D. Reed and D. Clark (1984), End-to-End Arguments in System Design, MIT Laboratory for Computer Science.

SEC (1997), AMAZON.COM, INC. REGISTRATION, https://www.sec.gov/Archives/edgar/data/1018724/0000891020-97-000839.txt (accessed on 15 October 2018).

Statcounter (2017), Search Engine Market Share Worldwide, http://gs.statcounter.com/searchengine-market-share (accessed on 12 October 2018).

Taplin, J. (2017), Move Fast And Break Things: How Facebook, Google, and amazon cornered culture and undermined democracy, Little, Brown and Company, New York.

The Economist (27 August 2016), Cloud chronicles, The Economist, https://www.economist.com/business/2016/08/27/cloud-chronicles (accessed on 20 December 2018).

The Learning Network (5 January 2012), "Henry Ford Implements the \$5-a-day wage, January 5 2012”, The New York Times, https://learning.blogs.nytimes.com/2012/01/05/jan-5-1914henry-ford-implements-5-a-day-wage/ (accessed on 12 October 2018).

The World Bank (2017), Trouble in the Making? The Future of Manufacturing-Led Development, http://dx.doi.org/10.1596/978-1-4648-1174-6.

Toffler, A. (1980), The Third Wave, Bantam Books, USA.

Tuomi, I. (4 November 2002), The Lives and Death of Moore's Law, http://firstmonday.org/ojs/index.php/fm/article/view/1000/921 (accessed on 15 October 2018)

Privacy Shield Framework (2017), US Department of Commerce website, https://www.privacyshield.gov/welcome (accessed on 20 December 2018).

UNCTAD (2018), "World Investment Report: Annex Tables", United Nations Conference on Trade and Development, http://unctad.org/en/Pages/DIAE/World\%20Investment\%20Report/Annex-Tables.aspx (accessed on 16 October 2018).

Van Alstyne, M., G. Parker and S. Choudary (2016), "Pipelines, Platforms, and the New Rules of Strategy", Harvard Business Review, https://hbr.org/2016/04/pipelines-platforms-and-thenew-rules-of-strategy (accessed on 20 December 2018). 
Van Ark, B. (2016), "The Productivity Paradox of the New Digital Economy", International Productivity Monitor, Vol. 31/3-18, https://econpapers.repec.org/article/slsipmsls/v 3a31 3ay 3a2016 3a1.htm (accessed on 21 December 2018).

Varian, H. (2017), Measurement Challenges in High Tech, https://www2.census.gov/adrm/fesac/2017-06-09/Varian-Presentation.pdf.

Vernon, R. (1971), Sovereignty at Bay: The Multinational Spread of U.S, Basic Books Enterprises, New York.

Wahba, P. (10 april 2017), "Amazon Will Make Up 50\% of All U.S. E-Commerce by 2021”, Fortune, http://fortune.com/2017/04/10/amazon-retail/ (accessed on 20 December 2018). 


\section{Notes}

${ }^{1}$ (Tuomi, 2002 [71]) illustrates this interrelationship by showing the evolution of the meaning of Moore's Law.

${ }^{2}$ See web table 19 in (UNCTAD, 2018 $\left.{ }_{[74]}\right)$.

3 "Since inception, the Company [AMAZON.COM, INC.] has incurred significant losses, and as of March 31, 1997 had an accumulated deficit of USD 9.0 million. The Company believes that its success will depend in large part on its ability to (i) extend its brand position, (ii) provide its customers with outstanding value and a superior shopping experience, and (iii) achieve sufficient sales volume to realize economies of scale. Accordingly, the Company intends to invest heavily in marketing and promotion, site development and technology and operating infrastructure development. The Company also intends to offer attractive pricing programs, which will reduce its gross margins. Because the Company has relatively low product gross margins, achieving profitability given planned investment levels depends upon the Company's ability to generate and sustain substantially increased revenue levels. As a result, the Company believes that it will incur substantial operating losses for the foreseeable future, and that the rate at which such losses will be incurred will increase significantly from current levels." (SEC, 1997[72]

${ }^{4}$ Data, in current prices, refer to the private market sector and follow the definition of INTANInvest, i.e. ISIC Rev.4 Divisions 01 to 82 excluding 68 and 72. Intensities are defined as investment over Gross Value Added as sourced from the OECD System of National Accounts (SNA) Database. Non-residential Gross Fixed Capital Formation (GFCF) is calculated as total GFCF excluding investment in Dwellings and Intellectual Property, and is sourced from the OECD System of National Accounts (SNA) Database. KBC assets in National Accounts are also sourced from the SNA Database, and correspond to the Intellectual Property GFCF. R\&D investment by sector for the United States is sourced from the U.S. Bureau of Economic Analysis. Data on Other KBC Assets are sourced from INTAN-Invest and extrapolated, where necessary, using the growth rate of Intellectual Property GFCF from the OECD SNA Database. "Other KBC Assets" include Design, New Financial Products, Brands, Training and Organisational Capital.

5 “[...] every device on the Internet should be able to exchange data packets with any other device that was willing to receive them." (Drake, 2016[90]) (Drake, Cerf and Kleinwächter, 2016 $6_{[73]}$ )

${ }^{6}$ See Fund for Investigative Journalism - http://fij.org/. 